Check for updates

Cite this: RSC Adv., 2017, 7, 48683

Received 24th August 2017

Accepted 7th October 2017

DOI: $10.1039 / c 7 r a 09380 b$

rsc.li/rsc-advances

\section{Synthesis of a 12-membered cyclic siloxane possessing alkoxysilyl groups as a nanobuilding block and its use for preparation of gas permeable membranes $\dagger$}

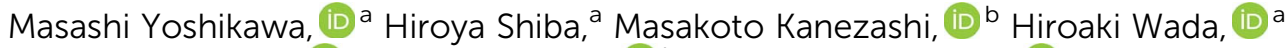 \\ Atsushi Shimojima, (D) ${ }^{a}$ Toshinori Tsuru (D) ${ }^{b}$ and Kazuyuki Kuroda (D) *ac
}

\begin{abstract}
A 12-membered cyclic siloxane possessing alkoxysilyl groups was synthesized as a nanobuilding block for siloxane-based materials by the alkoxysilylation of organometallasiloxane containing a 12-membered ring with $\mathrm{Si}-\mathrm{Me}$ and $\mathrm{Si}-\mathrm{O}^{-}$groups as the side groups. The cyclic structure was retained not only in the hydrolysis and condensation reactions (sol-gel process) of the alkoxysilyl groups but also in the xerogel and membrane preparation processes. The degree of condensation of the xerogel derived from the 12membered ring siloxane was higher than that derived from alkoxysilane monomers, indicating that the alkoxysilylated cyclic oligosiloxane is useful for controlling siloxane networks. A membrane composed of the cyclic siloxane was prepared by coating the hydrolyzed solution onto a porous alumina tube for evaluating the gas permeation properties. The membrane showed a molecular sieving effect for $\mathrm{H}_{2} / \mathrm{SF}_{6}$.
\end{abstract}

\section{Introduction}

Siloxane-based porous materials have been used in practical applications, such as catalysis, separation, and adsorption, ${ }^{1,2}$ because of their thermal and chemical stability and high compatibility with other materials (such as polymers, metals, and metal oxides) for composite formation. The properties of such materials depend on the structure of the siloxane network; therefore, the structural control at a molecular level is important.

The use of nanobuilding blocks with defined oligosiloxane structures is quite effective for controlling siloxane networks at the molecular level. ${ }^{3}$ This pathway provides unique materials that cannot be obtained from monomeric silicon compounds. Branched, cyclic, and cage-type oligosiloxanes have been synthesized and used as nanobuilding blocks for various siloxane-based nanomaterials. ${ }^{4,5}$ Among them, cyclic siloxanes are expected to act as nanobuilding blocks possessing inclusion

\footnotetext{
${ }^{a}$ Department of Applied Chemistry, Faculty of Science and Engineering, Waseda University, 3-4-1 Ohkubo, Shinjuku-ku, Tokyo 169-8555, Japan. E-mail: kuroda@ waseda.jp

${ }^{b}$ Department of Chemical Engineering, Graduate School of Engineering, Hiroshima University, 1-4-1 Kagami-yama, Higashi-Hiroshima 739-8527, Japan

'Kagami Memorial Research Institute for Materials Science and Technology, Waseda University, 2-8-26 Nishiwaseda, Shinjuku-ku, Tokyo, 169-0051, Japan

$\dagger$ Electronic supplementary information (ESI) available. Characterizations of 12MR-Me-TES, 12MR-Me-TES-derivedgels, TEOS-MTES-derived gels, and precursor of 12MR-Me-TES. Experimental apparatus for gas permeation measurement. See DOI: 10.1039/c7ra09380b
}

properties similar to cyclic organic compounds such as cyclodextrins and crown ethers. ${ }^{6}$ Actually, inclusion compounds composed of cyclic penta-, hexa-, and hepta-siloxanes and metal ions have been reported, ${ }^{7-9}$ which indicates that the cavity within cyclic siloxanes is accessible to some guest species. The inner spaces provided by larger cyclic siloxanes are expected to show unique host-guest interactions with various molecular species. In contrast to many reports concerning the use of organic host compounds (carbon based), the effective utilization of the cavity of cyclic siloxanes remains largely unexplored.

There have been many reports concerning the synthesis of cyclic siloxanes with various ring sizes. In this study, we have chosen a 12-membered cyclic siloxane as a nanobuilding block. The inside diameter of the 12-membered siloxane ring is roughly estimated to be $c a .0 .9 \mathrm{~nm}$ when the ring structure is fully extended and planar, $\$$ and the ring is larger than that of a benzene ring. The 12-membered cyclic siloxanes are easily obtained as complexes with metal cations by the hydrolysis and condensation of organotrialkoxysilanes in the presence of alkali metal hydroxide and transition metal cations. ${ }^{10,11}$ Despite the attractiveness of cyclic siloxanes, 12-membered cyclic siloxanes have rarely been used as nanobuilding blocks for the formation of siloxane-based materials to the best of our knowledge.

\footnotetext{
$\ddagger$ The 12-membered cyclic siloxane of complex shows a saddle conformation before silylation because of the interaction among $\mathrm{SiO}^{-}$groups and metal cations. After silylation, the cyclic structure can take an extended and planar state because such strong interactions to regulate the configuration does not work. The inside diameter of 12-membered cyclic siloxane is calculated by using Chem3D.
} 


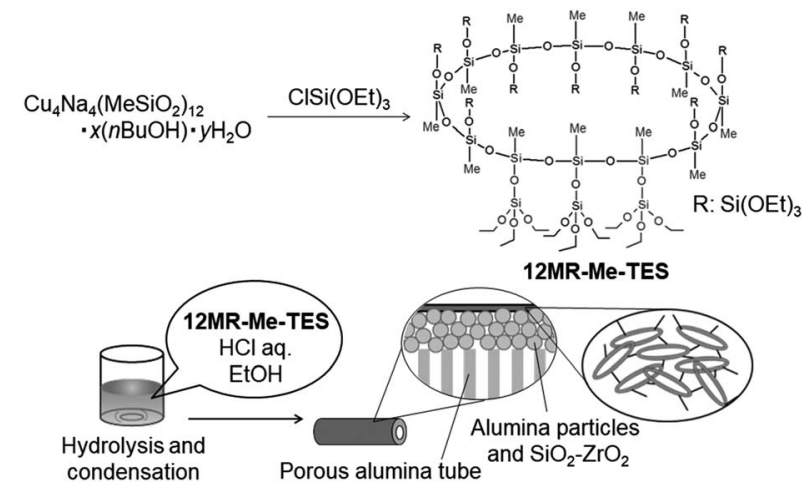

Scheme 1 Synthesis of the cyclic siloxane with alkoxysilyl groups and the membrane preparation.

Shchegolikhina et al. ${ }^{12,13}$ reported the preparation of layered compounds by the solid-phase condensation of 12-membered cyclic siloxanes possessing both hydroxy and phenyl groups. Zheng et al. prepared a porous polymer by the hydrosilylation polymerization of a 12-membered cyclic siloxane possessing both vinyl and hydrosilyl groups. ${ }^{14}$ Zheng et al. also reported a polymer by thiol-ene polymerization of a 12-membered cyclic siloxane possessing both vinyl and thiol groups. ${ }^{15}$ Unfortunately, these reports did not clarify the retention of the 12membered cyclic siloxane structure in the products.

In this study, a 12-membered cyclic siloxane with alkoxysilyl groups as side groups was synthesized as a new nanobuilding block by alkoxysilylation of the complex between 12-membered cyclic siloxane and metal cations (Scheme 1). Hereafter, the obtained compound is referred to as 12MR-Me-TES (based on 12-membered ring molecule possesses Methyl groups and TriEthoxySilyloxy (TES) groups as side groups). The hydrolysis and polycondensation processes of this compound were studied in detail by NMR spectroscopies to confirm that the ring structure was retained after the reaction. Furthermore, the cyclic siloxane was hydrolyzed and polycondensed onto a porous alumina tube to prepare composite membranes, and the membrane gas permeation properties were investigated to discuss the usefulness of the cyclic siloxane as a nanobuilding block.

\section{Results and discussion}

\section{Characterization of 12MR-Me-TES}

Fig. 1a shows the ${ }^{29} \mathrm{Si}$ NMR spectrum of 12MR-Me-TES. The two $\mathrm{T}^{3}$ signals (Fig. 1a, A and B) observed at $-67.43 \mathrm{ppm}$ and $-67.45 \mathrm{ppm}$ can be assigned to the Si atoms constituting the 12membered ring. No signal of the complex was observed in the $\mathrm{T}^{2}$ region (typically $-56.8 \mathrm{ppm}$ to $-58.8 \mathrm{ppm}$ (ref. 16-18)). The two $\mathrm{Q}^{1}$ signals (Fig. 1a, C and D) at $-88.95 \mathrm{ppm}$ and $-89.04 \mathrm{ppm}$ are due to the Si atoms of the TES groups. The two slightly different environments for both $\mathrm{T}^{3}$ and $\mathrm{Q}^{1}$ units can be attributed to the up-and-down arrangement of the side TES groups on the 12membered ring siloxane, as shown in Fig. 1a. Please note that the arrangement of side groups against the 12-membered ring plane switches every three $\mathrm{Si}-\mathrm{O}$ bonds. The intensity ratio of the ${ }^{29} \mathrm{Si}$ NMR signals $((\mathrm{A}+\mathrm{B}): \mathrm{C}: \mathrm{D}=12: 4: 8)$ is consistent with the structure.§ These results strongly suggest that the alkoxysilylation of $\mathrm{Cu}_{4} \mathrm{Na}_{4}\left(\mathrm{MeSiO}_{2}\right)_{12} \cdot x(n \mathrm{BuOH}) \cdot y \mathrm{H}_{2} \mathrm{O}$ proceeds with the retention of the 12-membered ring structure, including the up-and-down arrangement of side groups.

The ${ }^{1} \mathrm{H}$ NMR spectrum of 12MR-Me-TES (Fig. 1b) shows four signals assigned to ethoxy groups (3.83-3.79 ppm for $-\mathrm{OCH}_{2} \mathrm{CH}_{3}, 1.22-1.19 \mathrm{ppm}$ for $\left.-\mathrm{OCH}_{2} \mathrm{CH}_{3}\right)$ and methyl groups $(0.26 \mathrm{ppm}$ and $0.25 \mathrm{ppm})$. The intensity ratio of these signals is in accordance with the calculated ratio. The two different environments for the methyl carbons are consistent with the structure, as mentioned above. Regarding the ethoxy groups, the separation of the signals was too small to be observed clearly. These ${ }^{1} \mathrm{H}$ NMR results, together with the ${ }^{13} \mathrm{C}$ NMR results (Fig. S1 in the ESI $\dagger$ ), also support the formation of 12MRMe-TES.

The high-resolution electrospray ionization mass spectroscopy (ESI-MS) spectrum of 12MR-Me-TES shows a peak at $\mathrm{m} / \mathrm{z}=$ 2879.8320, corresponding to the sodium adduct of 12MR-MeTES (calcd. for 2879.8205), confirming that 12MR-Me-TES had been successfully synthesized. This is the first report concerning the synthesis of a 12-membered ring siloxane possessing alkoxysilyl groups that is available as a sol-gel precursor of siloxane-based materials. This synthetic procedure is applicable to the alkoxysilylation of metalorganosiloxanes possessing cyclic siloxane structures other than 12-membered rings, ${ }^{19-23}$ which could result in the variation of bond densities and angles of the formed siloxane networks.

\section{Hydrolysis and polycondensation of 12MR-Me-TES}

To investigate the behavior of 12MR-Me-TES in the sol-gel process, the hydrolysis and polycondensation of 12MR-Me-TES in solution was analyzed by liquid-state NMR spectroscopies. Fig. 2 shows the ${ }^{13} \mathrm{C}$ NMR spectra of the hydrolyzed solution of 12MR-Me-TES. The signal intensity arising from the methylene carbon of the TES groups at $59.6 \mathrm{ppm}$ decreased, and the intensity of the signal corresponding to the methylene carbon of ethanol (57.7 ppm) increased as the reaction time progressed. The signals arising from the TES groups almost disappeared after $3 \mathrm{~h}$, which indicates the complete hydrolysis of the TES groups of 12MR-Me-TES. The signal arising from the -SiMe groups broadened with reaction time. The signal broadening is also confirmed by the ${ }^{29} \mathrm{Si}$ NMR data (next paragraph).

Fig. 3 shows the ${ }^{29} \mathrm{Si}$ NMR spectra of the hydrolyzed solution of 12MR-Me-TES. Three new signals are observed in the $\mathrm{Q}$ region $(-85 \mathrm{ppm}$ to $-93 \mathrm{ppm})$ after $1 \mathrm{~h}$, in addition to the original signal arising from the TES groups of 12MR-Me-TES

$\S$ Two TES groups located in the end of the continuous three TES groups (Q unit), facing to the same direction against 12-membered ring plane, are set in the cis and trans positions against both of the adjacent TES groups. The center TES groups are in the cis position against both of the adjacent TES groups. Hence, the signals due to TES groups are observed at $-88.95 \mathrm{ppm}$ and $-89.04 \mathrm{ppm}$, and signal intensity ratio of these signals is $1: 2$. In addition, magnification of the signal due to the $\mathrm{Si}$ atoms ( $\mathrm{T}$ unit) of 12-membered ring exhibits the presence of the shoulder signal probably due to the conformation. 
(a)
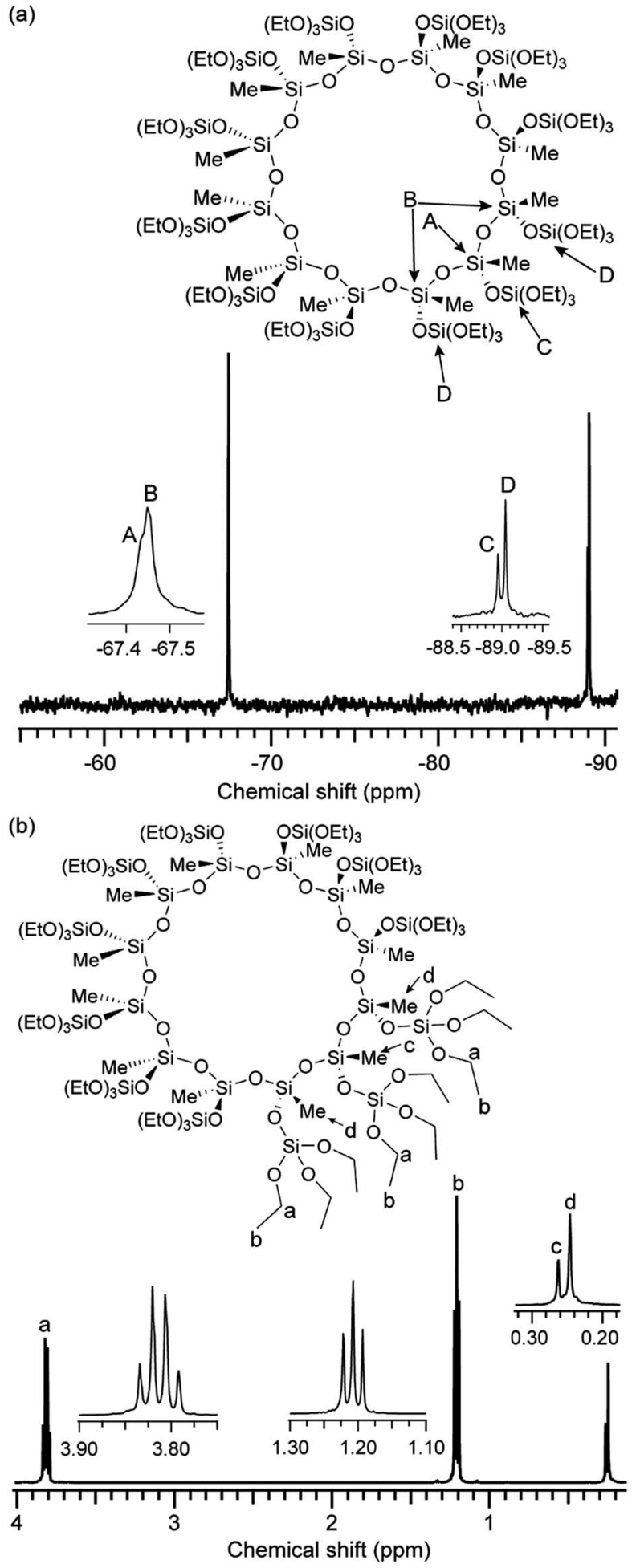

Fig. 1 NMR spectra of $12 \mathrm{MR}-\mathrm{Me}-\mathrm{TES}$. (a) ${ }^{29} \mathrm{Si}$ and (b) ${ }^{1} \mathrm{H}$.

$(-88.8 \mathrm{ppm})$. The new signals at $-86.3 \mathrm{ppm},-90.7 \mathrm{ppm}$, and $-92.8 \mathrm{ppm}$ can be assigned to $-\operatorname{SiOSi}(\mathrm{OEt})_{2}(\mathrm{OH}),-\operatorname{SiOSi}(\mathrm{OEt})-$ $(\mathrm{OH})(\mathrm{OSi})$, and $-\mathrm{SiOSi}(\mathrm{OH})_{2}(\mathrm{OSi})$, respectively, ${ }^{17,24}$ which indicates that the partial hydrolysis and condensation of the TES groups of 12MR-Me-TES had occurred. Meanwhile, the $\mathrm{T}^{3}$ signals corresponding to the $\mathrm{Si}$ atoms of the 12-membered ring

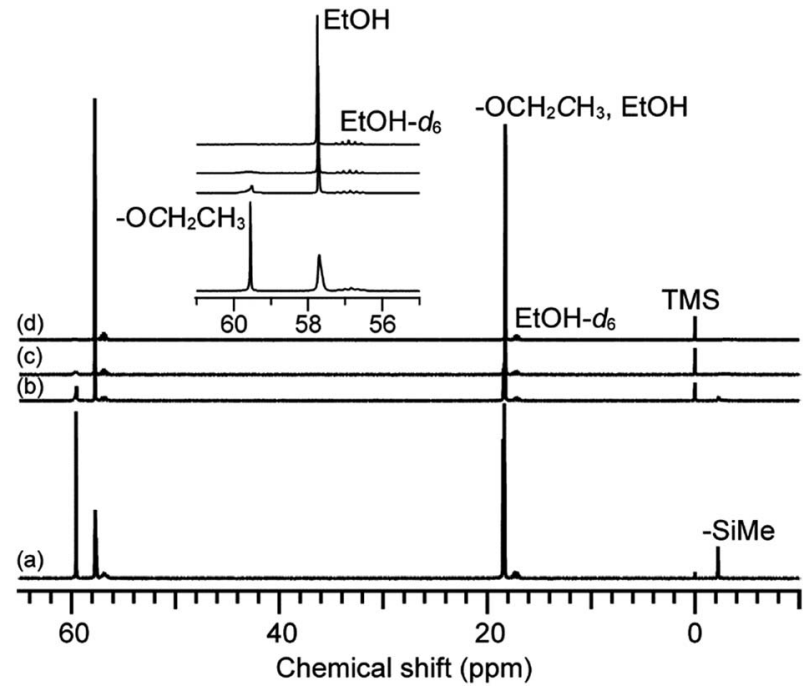

Fig. $2{ }^{13} \mathrm{C}$ NMR spectra of the hydrolyzed solution of $12 \mathrm{MR}-\mathrm{Me}-\mathrm{TES}$. (a) $0 \mathrm{~h}$, (b) $1 \mathrm{~h}$, (c) $3 \mathrm{~h}$, and (d) $6 \mathrm{~h}$.

are observed. After $3 \mathrm{~h}$ and $6 \mathrm{~h}$, all signals had weakened and broadened. This is caused by the following two factors: (i) the types of hydrolyzed and condensed molecules become more diverse with the progress of hydrolysis and condensation, and (ii) the molecular mobility of the condensed species is decreased by the increasing molecular weight as intermolecular condensation progresses or the rigidity of the cyclic siloxane increases through intramolecular condensation. During the reaction, no $\mathrm{T}^{2}$ signals arising from the cleavage of the $\mathrm{Si}-\mathrm{O}-\mathrm{Si}$ bonds appeared (the $\mathrm{T}^{2}$ signal of the Si atom possessing methyl group is generally observed at $-56 \mathrm{ppm}$ to $-58 \mathrm{ppm}$ ), which suggests that the cyclic structure of 12MR-Me-TES is retained without rearrangement. Even if the rearrangement occurred too rapidly to observe by NMR spectroscopy, chemical shift of $\mathrm{T}^{3}$

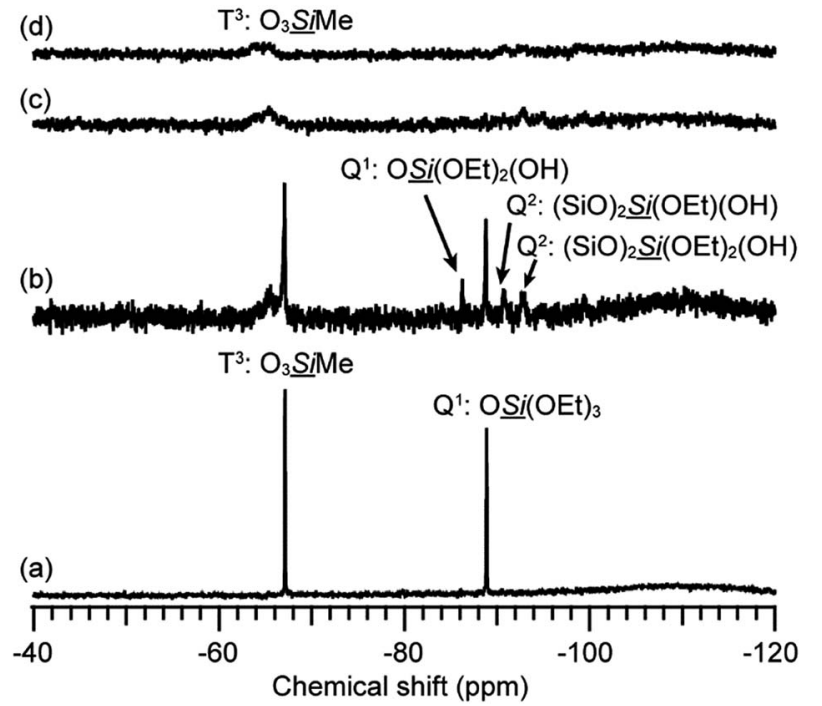

Fig. $3{ }^{29} \mathrm{Si} \mathrm{NMR}$ spectra of the hydrolyzed solution of $12 \mathrm{MR}-\mathrm{Me}-\mathrm{TES}$. (a) $0 \mathrm{~h}$, (b) $1 \mathrm{~h}$, (c) $3 \mathrm{~h}$, and (d) $6 \mathrm{~h}$. 
silicon in reformed siloxanes bonds would not be shifted to downfield by $3 \mathrm{ppm}$. Regarding to the downfield shift of $\mathrm{T}^{3}$ signals, there are a couple of explanations. One probable reason is cyclization of adjacent TES groups to form four-membered rings. The other probable reason is the gradual progress of hydrolysis and condensation of TES groups, and this variation in the $\mathrm{Q}$ units must affect the electronic states of linked neighboring $\mathrm{T}^{3}$ silicons. Because -SiOH and-SiOSi groups show a more electron-withdrawing effect than TES group, the signals due to $\mathrm{T}^{3}$ silicon can be shifted to downfield. Therefore, the downfield shift observed in this study can be explained by the variations in the electron density during the sol-gel reaction. These results indicate that the cyclic structure of 12MR-Me-TES is retained after the sol-gel reactions, which is important for the preparation of separation/adsorption media using siloxane oligomers.

\section{Characterization of the 12MR-Me-TES-derived gels and tetraethoxysilane-methyltriethoxysilane-derived gels}

The stability of the 12-membered ring units in the gels derived from 12MR-Me-TES was investigated. The hydrolyzed solution of 12MR-Me-TES was dried to obtain a xerogel (12MR-gel-as). Subsequently, the obtained gel was heated at $100^{\circ} \mathrm{C}, 200^{\circ} \mathrm{C}$, or $300{ }^{\circ} \mathrm{C}$ under an argon atmosphere (12MR-gel-heat100, 12MRgel-heat200, and 12MR-gel-heat300, respectively). These samples were analyzed by solid-state ${ }^{29} \mathrm{Si}$ NMR spectroscopy. 12MR-gel-as was obtained by drying the solution containing hydrolyzed and partially polycondensed 12MR-Me-TES. Please note that the reaction conditions were different from those used for the investigation of hydrolysis process described in the previous section. The hydrolysis conditions in this section were the same conditions as those for the preparation of the 12MRMe-TES-derived membrane precursor sol. The larger amount of solvent (ethanol) in these systems is favorable for the suppression of the hydrolytic cleavage of the 12-membered ring. The ${ }^{29}$ Si magic angle spinning (MAS) NMR spectrum of 12MR-gel-as shows $\mathrm{T}$ and $\mathrm{Q}$ signals (Fig. 4a). Three signals are observed in the $\mathrm{Q}$ region $\left(\mathrm{Q}^{2}, \mathrm{Q}^{3}\right.$, and $\left.\mathrm{Q}^{4}\right)$, indicating the progress of hydrolysis and polycondensation of 12MR-Me-TES; however, the appearance of $\mathrm{Q}^{2}$ and $\mathrm{Q}^{3}$ signals indicates these reactions had not completed and -SiOEt and -SiOH groups remained. In the $\mathrm{T}$ region, only the $\mathrm{T}^{3}$ signal corresponding to the $\mathrm{Si}$ atoms in the 12-membered rings was observed, suggesting that the 12membered ring structure of 12MR-Me-TES had been retained.

The signals assigned to ethoxy groups are observed in the ${ }^{13} \mathrm{C}$ cross-polarization (CP)/MAS NMR spectrum (Fig. S2a in the ESI $\dagger$ ), which indicates that the hydrolysis of 12MR-Me-TES had not completed. As described in the previous section, the hydrolysis reaction was completed under the conditions for the investigation of hydrolysis and polycondensation process of 12MR-Me-TES. Such a difference in the degree of hydrolysis can be explained by the difference in the concentrations of the $\mathrm{HCl}$ catalyst. The concentration of $\mathrm{HCl}$ in the reaction mixture for the preparation of the 12MR-Me-TES-derived gel $(\mathrm{HCl} /(\mathrm{EtOH}+$ $\left.\mathrm{H}_{2} \mathrm{O}\right)=6.3 \times 10^{-5}$ ) is much lower than that for the investigation of hydrolysis process of 12MR-Me-TES $\left(\mathrm{HCl} /\left(\mathrm{EtOH}+\mathrm{H}_{2} \mathrm{O}\right)=\right.$
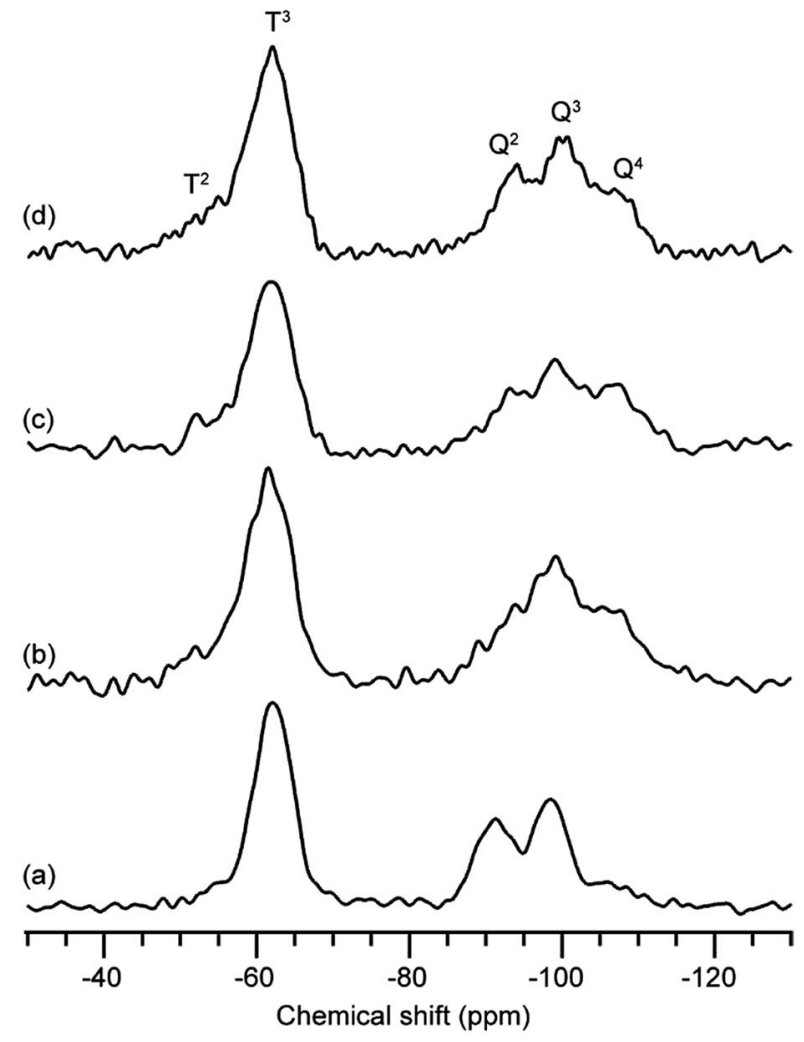

Fig. $4{ }^{29}$ Si MAS NMR spectra of 12MR-Me-TES-derived gel. (a) 12MRgel-as, (b) 12MR-gel-heat100, (c) 12MR-gel-heat200, and (d) 12MRgel-heat300.

$3.0 \times 10^{-3}$ ). Even the reaction time was increased from $1 \mathrm{~d}$ to $2 \mathrm{~d}$, the ethoxy groups remained $\left({ }^{13} \mathrm{C} \mathrm{CP} / \mathrm{MAS}\right.$ NMR: Fig. $\mathrm{S} 4$ in the ESI $\dagger$ ), and the partial cleavage of the 12-membered ring occurred ( ${ }^{29} \mathrm{Si}$ MAS NMR: Fig. S5 in the ESI $\dagger$ ). To avoid this cleavage, it is important to induce gelation after $1 \mathrm{~d}$ by evaporating the solvent.

After the heat treatment of 12MR-gel-as under an argon atmosphere, the polycondensation progress was confirmed by ${ }^{29} \mathrm{Si}$ MAS NMR and Fourier-transform infrared (FT-IR) spectroscopies, which demonstrates the reduction in the number of $\mathrm{SiOH}$ groups (Fig. 4b-d and S3 in the ESI, respectively $\dagger$ ), although some ethoxy groups remained (Fig. S2b-d in the ESI $\dagger$ ). In the case of 12MR-gel-heat100, only the $\mathrm{T}^{3}$ signal was observed, in common with 12MR-gel-as (Fig. 4b), indicating that the 12-membered ring structure of 12MR-gel-as did not deteriorate at $100{ }^{\circ} \mathrm{C}$. On the other hand, at higher temperatures, small $\mathrm{T}^{2}$ signals appeared in the ${ }^{29} \mathrm{Si}$ MAS NMR spectra of both 12MR-gel-heat200 and 12MR-gel-heat300 (Fig. 4c and d, respectively). It is likely that the 12 -membered rings were cleaved by increasing strain arising from the progress of polycondensation with heating.

For comparison, equimolar amounts of tetraethoxysilane (TEOS) and methyltriethoxysilane (MTES) were co-hydrolyzed and polycondensed to obtain a xerogel. The ${ }^{29} \mathrm{Si}$ MAS NMR analysis confirmed that the signal intensity of the $\mathrm{T}^{2}$ silicon atom of TEOS-MTES-derived gel (Fig. S6 in the ESI $\dagger$ ) is higher than that of 12MR-Me-TES-derived gel (Fig. 4). The lack of $\mathrm{T}^{2}$ 
silicon atoms in the 12MR-Me-TES-derived gel can be attributed to the usage of 12MR-Me-TES having only $\mathrm{T}^{3}$ silicon atoms as a precursor under controlled conditions. These results indicate that the cyclic oligosiloxanes, which are composed of silicon atoms with controlled condensation degree, are useful precursors to control the siloxane networks.

\section{Gas permeation properties of 12MR-Me-TES-derived membranes and TEOS-MTES-derived membranes}

The gas permeance of the 12MR-Me-TES-derived membranes was evaluated at $100{ }^{\circ} \mathrm{C}$, and the influence of the heat treatment of the membranes was investigated. Fig. 5 shows the gas permeances of the 12MR-Me-TES-derived membranes heated at $100^{\circ} \mathrm{C}, 200^{\circ} \mathrm{C}$, and $300{ }^{\circ} \mathrm{C}$ as a function of kinetic diameter. There are no significant changes in both the shape of these curves and the selectivity with heating temperature (e.g., $\mathrm{H}_{2} / \mathrm{SF}_{6}: 550,700$, and 650 for the membranes heated at $100{ }^{\circ} \mathrm{C}, 200{ }^{\circ} \mathrm{C}$, and $300{ }^{\circ} \mathrm{C}$, respectively). The selectivity for $\mathrm{H}_{2} / \mathrm{SF}_{6}$ shows higher values than the expected value for Knudsen diffusion $\left(\mathrm{H}_{2} / \mathrm{SF}_{6}\right.$ Knudsen selectivity: 6 (ref. 25)), indicating that the 12MR-Me-TES-derived membranes show a molecular sieving effect.

The slopes of the gas permeances against the kinetic diameter were almost the same, and the gas permeances were increased with increasing heat treatment temperature (Fig. 5). The former result indicates that the average pore diameter of the membrane does not depend on the heating temperature. Assuming that gas molecules pass through the inner space of 12-membered ring siloxanes, the slope of gas permeances against kinetic diameter would decrease with the cleavage of the 12-membered ring siloxanes. Actually, the 12-membered ring siloxanes are slightly cleaved by heat treatments at $200{ }^{\circ} \mathrm{C}$ and $300{ }^{\circ} \mathrm{C}$, as shown in Fig. 4; however, the slopes were almost the same (Fig. 5). This could indicate that the relative positions of the $\mathrm{Si}$ atoms in the 12-membered ring siloxane of 12MR-Me-TES were not changed significantly by the cleavage of the cyclic

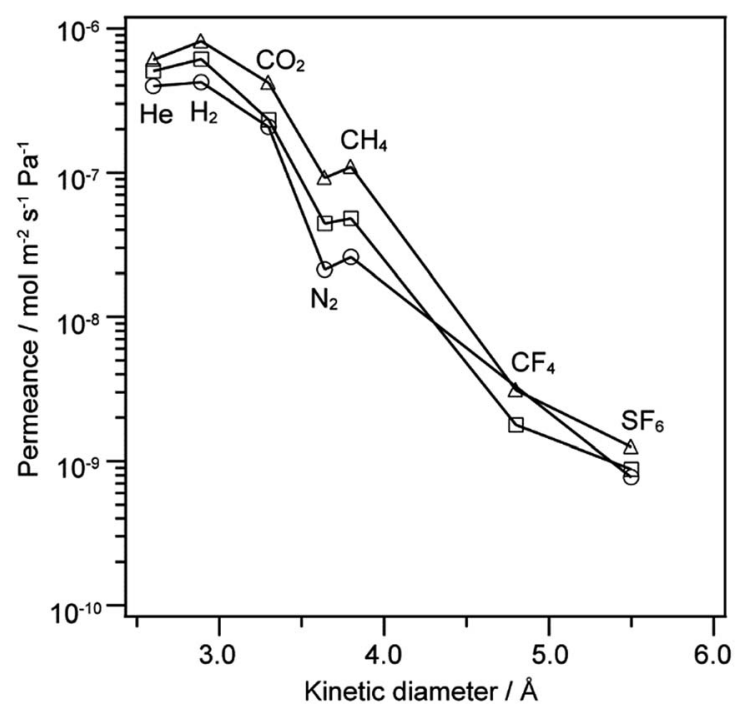

Fig. 5 Gas permeance at $100{ }^{\circ} \mathrm{C}$ for $12 \mathrm{MR}-\mathrm{Me}-\mathrm{TES}$-derived membranes as a function of molecular size. The membranes are heated at $100{ }^{\circ} \mathrm{C}$ (circle), $200{ }^{\circ} \mathrm{C}$ (square), and $300{ }^{\circ} \mathrm{C}$ (triangle). siloxanes with heat treatment. The increase in the permeance with increasing heating temperature is probably due to the desorption of adsorbed water with heat treatment, which is often observed for sol-gel derived membranes. ${ }^{26}$

The physical adsorption of gas molecules affects the gas permeance measured at $100{ }^{\circ} \mathrm{C}$ (Fig. 5), but the effect can be ignored at $200{ }^{\circ} \mathrm{C}$ and higher. The gas permeation experiments at $100{ }^{\circ} \mathrm{C}$ show that the permeance of 12MR-Me-TES-derived membranes does not depend on their heating temperature; therefore, the gas permeance of the 12MR-Me-TES-derived membranes was evaluated at $200{ }^{\circ} \mathrm{C}$.

TEOS-MTES-derived membrane was fabricated by hydrolysis and co-condensation of TEOS and MTES, and its gas permeance was also evaluated for comparison. Fig. 6a shows the gas
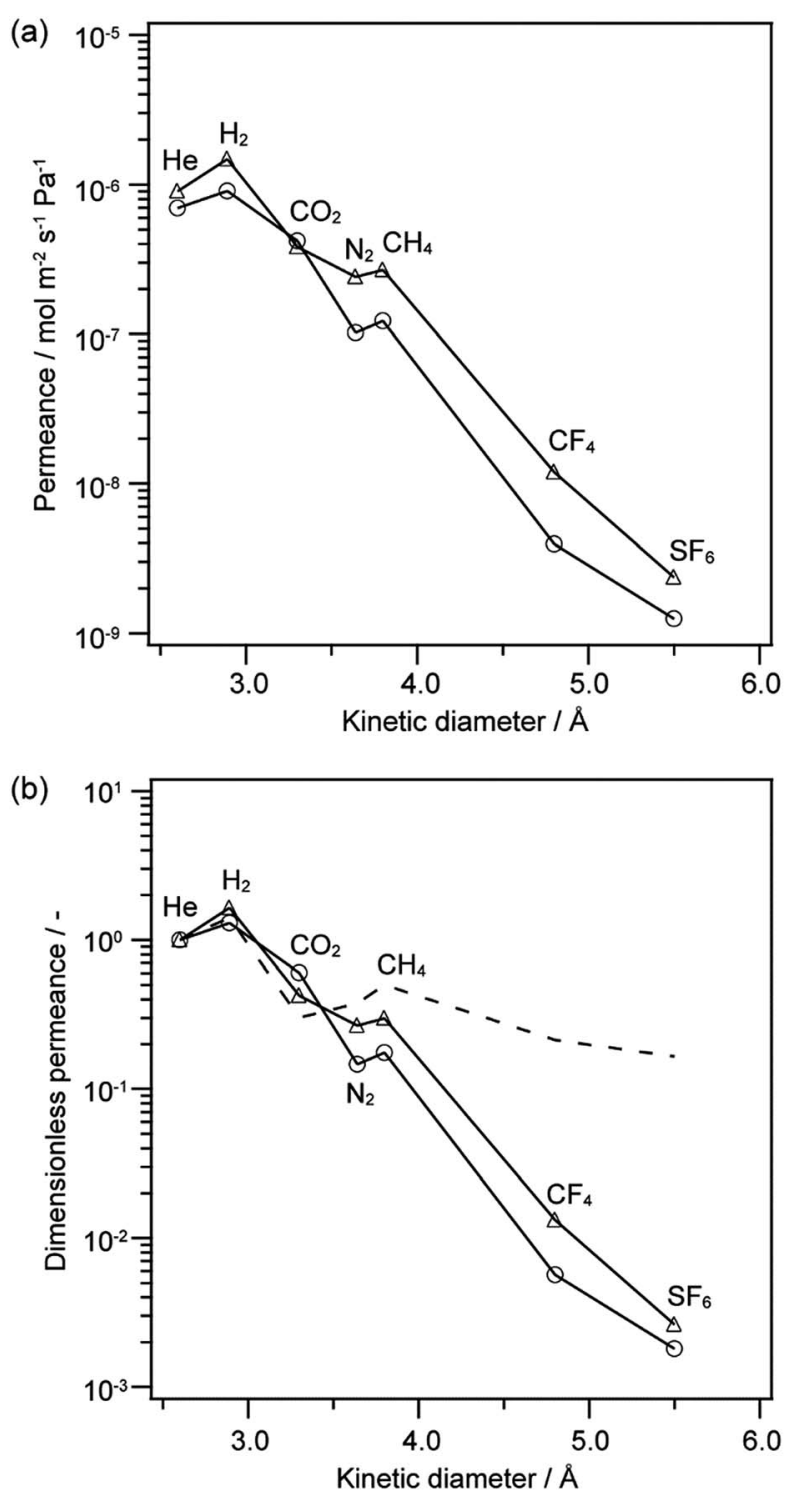

Fig. 6 (a) Gas permeance and (b) dimensionless permeance based on He permeance at $200^{\circ} \mathrm{C}$ as a function of molecular size. (circle) $12 \mathrm{MR}$ Me-TES-derived membrane heated at $300^{\circ} \mathrm{C}$, (triangle) TEOS-MTESderived membrane, and (broken line) calculated dimensionless permeance under Knudsen mechanism based on $\mathrm{He}$ (the calculation is based on ref. 25). 
permeances of the 12MR-Me-TES-derived membrane and TEOSMTES-derived membrane as a function of kinetic diameter. Both membranes were heated at $300{ }^{\circ} \mathrm{C}$ after the coating of sols onto porous alumina tubes. Fig. $6 \mathrm{~b}$ shows the dimensionless permeances based on the $\mathrm{He}$ permeance at $200{ }^{\circ} \mathrm{C}$ for these membranes. Compared with dimensionless permeance under the Knudsen mechanism, both membranes showed low dimensionless permeance between $\mathrm{N}_{2}$ and $\mathrm{SF}_{6}$, which indicates that both membranes showed a molecular sieving effect. The 12MRMe-TES membrane showed approximately the same level of gas permeance and pore size distribution with that of TEOS-MTES membrane. There are two possible reasons for the similar permeances. (i) The flexibility of siloxane or (ii) the formation of smaller cyclic structure than the 12-membered ring among 12MR-Me-TES during the condensation of 12MR-Me-TES. (i) The shape of such a large cyclic siloxane easily changes; in fact, the precursor of the 12MR-Me-TES-derived membrane $\left(\mathrm{Cu}_{4} \mathrm{Na}_{4}\left(\mathrm{MeSiO}_{2}\right)_{12} \cdot x(n \mathrm{BuOH}) \cdot y \mathrm{H}_{2} \mathrm{O}\right)$ contains a bending 12membered ring siloxane. So, the inner space of the 12-membered cyclic siloxane may be narrowed and/or distorted by the bending of the ring structure during the sol-gel reaction. (ii) When cyclic siloxanes smaller than the 12-membered ring are formed between the intermolecular spaces of 12MR-Me-TES, the gas permeance is underestimated by the averaging of the 12membered rings and the small intermolecular ring structures. The inclusion of some guest species into the ring before polymerization will be effective for the polymerization of extended 12-membered ring structures, which is now under investigation. In addition, intermolecular spacing among cyclic oligomers is quite important and should be further studied, although the present study suggests that there are no large spaces among the cyclic oligomers, as judged from the permeance data, which is promising for future research on the molecular design of nanobuilding block approach based on ring-type oligosiloxanes.

\section{Conclusions}

An alkoxysilylated 12-membered ring siloxane was successfully synthesized as a nanobuilding block for siloxane-based materials. The cyclic structure of the molecule can be retained during the sol-gel reaction and membrane preparation processes, which indicates that the cyclic siloxane is a useful precursor for siloxane-based materials with controlled structures. A membrane composed of the cyclic siloxane was fabricated, and the membrane showed molecular sieving effect for $\mathrm{H}_{2} / \mathrm{SF}_{6}$. These results demonstrate that oligomeric siloxanes with relatively large ring structures are useful nanobuilding blocks for nanomaterials. Further studies on the control of extended ring structure with precisely controlled arrangements are underway for the creation of functional siloxane-based nanomaterials.

\section{Experimental}

\section{Materials}

1-Butanol (>99.0\%), chloroform (>99.0\%), deuterated ethanol (EtOH- $d_{6}>99.5 \%$ ), ethanol (dehydrated $>99.5 \%$ ), hydrochloric acid (6 mol L ${ }^{-1} \mathrm{HCl}$ aq.), sodium hydroxide $(\mathrm{NaOH}>97.0 \%)$, toluene (dehydrated $>99.5 \%$ ), and pyridine (dehydrated $>99.5 \%$ ) were purchased from Wako Pure Chemical Industries, Ltd. and used as received. Chlorotrimethylsilane (>98.0\%), tetrachlorosilane $\left(\mathrm{SiCl}_{4}>98.0 \%\right.$ ), tetraethoxysilane (TEOS $>96.0 \%$ ), triethoxymethylsilane (MTES $>98.0 \%$ ), and zirconium tetrabutoxide (80\% ZrBT in 1-butanol) were purchased from Tokyo Chemical Industry Co., Ltd. and used as received. Copper(II) chloride $\left(\mathrm{CuCl}_{2}>97 \%\right)$ was purchased from Sigma-Aldrich Co., LLC. and used as received. The $\alpha$-alumina powders were purchased from Sumitomo Chemical Co., Ltd. The $\mathrm{SiO}_{2}-\mathrm{ZrO}_{2}$ sol was obtained by hydrolysis and condensation of tetraethoxysilane and zirconium tetrabutoxide. The detailed sol preparation procedure has been described previously. ${ }^{27,28}$ Porous $\alpha$-alumina tubes (HU-A01, average pore size: $2.1 \mu \mathrm{m}$, outside diameter: 10 $\mathrm{mm}$ ) were kindly supplied by the NIKKATO CORPORATION.

\section{Synthesis of $\mathrm{Cu}_{4} \mathrm{Na}_{4}\left(\mathrm{MeSiO}_{2}\right)_{12} \cdot x(n \mathrm{BuOH}) \cdot y \mathrm{H}_{2} \mathrm{O}$}

$\mathrm{Cu}_{4} \mathrm{Na}_{4}\left(\mathrm{MeSiO}_{2}\right)_{12} \cdot x(n \mathrm{BuOH}) \cdot y \mathrm{H}_{2} \mathrm{O}$ was synthesized according to the literature reported by Shchegolikhina et al. ${ }^{29}$ 1-Butanol (80 mL), NaOH (2.01 g, $50.2 \mathrm{mmol})$, and water $(2.72 \mathrm{~mL}, 150.9$ $\mathrm{mmol}$ ) were mixed in a three-neck flask equipped with a reflux condenser. After stirring the mixture for $30 \mathrm{~min}$ at room temperature, a solution of MTES $(10 \mathrm{~mL}, 50.3 \mathrm{mmol})$ in $20 \mathrm{~mL}$ of 1-butanol was added to the mixture with vigorous stirring. Then, $7.24 \mathrm{~mL}$ of water was added to the mixture, and it was heated to reflux. A solution of $\mathrm{CuCl}_{2}(2.24 \mathrm{~g}, 16.7 \mathrm{mmol})$ in $60 \mathrm{~mL}$ of 1-butanol was added dropwise over ca. $20 \mathrm{~min}$, and the mixture was refluxed for an additional $30 \mathrm{~min}$. The hot solution was filtered to remove precipitates, and the filtrate was cooled to room temperature. The filtrate was evaporated in a rotary evaporator, and then the residue was dried in vacuo at $90{ }^{\circ} \mathrm{C}$. A blue powder $\left(\mathrm{Cu}_{4} \mathrm{Na}_{4}\left(\mathrm{MeSiO}_{2}\right)_{12} \cdot x(n \mathrm{BuOH}) \cdot y \mathrm{H}_{2} \mathrm{O}\right)$ was obtained. The X-ray diffraction (XRD) pattern of the obtained blue powder was not consistent with that of $\mathrm{Cu}_{4} \mathrm{Na}_{4}\left(\mathrm{MeSiO}_{2}\right)_{12}$ $\cdot x(n \mathrm{BuOH}) \cdot y \mathrm{H}_{2} \mathrm{O}$ reported by Shchegolikhina et al. ${ }^{29}$ (Fig. $\mathrm{S} 8$ in the ESI $\dagger$ ), probably because of the difference in the number of solvated molecules (1-butanol and/or $\mathrm{H}_{2} \mathrm{O}$ ). To confirm the formation of the 12-membered cyclic siloxane structure, the product was silylated with chlorotrimethylsilane (detailed method and characterization are shown in ESI $\dagger$ ). The ${ }^{1} \mathrm{H},{ }^{13} \mathrm{C}$, and ${ }^{29} \mathrm{Si}$ NMR and MS data of the trimethylsilylated compound coincided with those of the reported compound; ${ }^{29}$ therefore, we concluded that the blue powder synthesized here possessed the 12-membered ring siloxane structure.

\section{Synthesis of chlorotriethoxysilane $\left(\mathrm{ClSi}(\mathrm{OEt})_{3}\right)$}

$\mathrm{ClSi}(\mathrm{OEt})_{3}$ was synthesized by the alkoxylation of $\mathrm{SiCl}_{4}$ with ethanol under a nitrogen atmosphere. Tetrachlorosilane (16.5 mL, $143.7 \mathrm{mmol}$ ) was added to a Schlenk flask under a $\mathrm{N}_{2}$ atmosphere, and the flask was cooled to $0{ }^{\circ} \mathrm{C}$. Dehydrated ethanol $(29.3 \mathrm{~mL}, 501.8 \mathrm{mmol})$ was added dropwise with stirring at $0{ }^{\circ} \mathrm{C}$. After the ethanol had been added, the mixture was stirred at $0{ }^{\circ} \mathrm{C}$ for $1 \mathrm{~h}$ and at room temperature for $4 \mathrm{~h}$. A colorless clear liquid was obtained. In this procedure, an excess of ethanol (3.5 eq.) was used to avoid the formation of diethoxydichlorosilane $\left(\mathrm{Cl}_{2} \mathrm{Si}(\mathrm{OEt})_{2}\right)$ because $\mathrm{Cl}_{2} \mathrm{Si}(\mathrm{OEt})_{2}$ leads to 
intermolecular crosslinking between $\mathrm{Cu}_{4} \mathrm{Na}_{4}\left(\mathrm{MeSiO}_{2}\right)_{12}$ $\cdot x(n \mathrm{BuOH}) \cdot y \mathrm{H}_{2} \mathrm{O}$ at the silylation step. Although tetraethoxysilane (TEOS) was also formed with $\mathrm{ClSi}(\mathrm{OEt})_{3}$ (approximately TEOS : $\mathrm{ClSi}(\mathrm{OEt})_{3}=1: 1$, the mixture was used for the silylation without purification because TEOS is much less reactive than $\mathrm{ClSi}(\mathrm{OEt})_{3}$. The formation of $\mathrm{ClSi}(\mathrm{OEt})_{3}$ was confirmed by ${ }^{1} \mathrm{H},{ }^{13} \mathrm{C}$, and ${ }^{29} \mathrm{Si}$ NMR spectroscopies.

\section{Synthesis of the 12-membered ring siloxane possessing alkoxysilyl groups (12MR-Me-TES)}

$\mathrm{Cu}_{4} \mathrm{Na}_{4}\left(\mathrm{MeSiO}_{2}\right)_{12} \cdot x(n \mathrm{BuOH}) \cdot y \mathrm{H}_{2} \mathrm{O}$ was alkoxysilylated with $\mathrm{ClSi}(\mathrm{OEt})_{3}$. Dehydrated toluene $(40 \mathrm{~mL})$ and dehydrated pyridine $(17 \mathrm{~mL}, 210.6 \mathrm{mmol})$ were added to $\mathrm{ClSi}(\mathrm{OEt})_{3}$ in a Schlenk flask. Then, $\mathrm{Cu}_{4} \mathrm{Na}_{4}\left(\mathrm{MeSiO}_{2}\right)_{12} \cdot x(n \mathrm{BuOH}) \cdot y \mathrm{H}_{2} \mathrm{O}(1.06 \mathrm{~g})$ was added to the solution, and blue-green colored precipitates were formed. The mixture was stirred for $48 \mathrm{~h}$ at room temperature under $\mathrm{N}_{2}$ atmosphere. Then, an excess of dehydrated pyridine and dehydrated ethanol were added to the mixture for the ethoxylation of the remaining $\mathrm{ClSi}(\mathrm{OEt})_{3}$. The precipitates were filtered with a glass filter under $\mathrm{N}_{2}$ atmosphere. Then, the solvent, unreacted pyridine, ethanol, and the following two byproducts ((1) TEOS, generated by the ethoxylation of $\mathrm{ClSi}(\mathrm{OEt})_{3}$, and (2) hexaethoxydisiloxane, formed by the reaction between $\mathrm{ClSi}(\mathrm{OEt})_{3}$ and adsorbed water from $\left.\mathrm{Cu}_{4} \mathrm{Na}_{4}\left(\mathrm{MeSiO}_{2}\right)_{12} \cdot x(n \mathrm{BuOH}) \cdot y \mathrm{H}_{2} \mathrm{O}\right)$ were removed in vacuo. A small amount of the precipitate was removed by syringe filtration. Finally, the alkoxysilylated 12-membered ring siloxane was isolated by gel permeation chromatography (GPC) using chloroform as an eluent (colorless clear viscous liquid, $1.8902 \mathrm{~g}$, yield: $78 \%$ ).

12MR-Me-TES. $\delta_{\mathrm{H}}\left(500.13 \mathrm{MHz} ; \mathrm{CDCl}_{3} ; \mathrm{TMS}\right) 0.25(\mathrm{~s}, 24 \mathrm{H}$, $\left.\mathrm{SiCH}_{3}\right), 0.26\left(\mathrm{~s}, 12 \mathrm{H}, \mathrm{SiCH}_{3}\right), 1.21(\mathrm{t}, J=7.0 \mathrm{~Hz}, 108 \mathrm{H}$, $\left.\mathrm{OCH}_{2} \mathrm{CH}_{3}\right), 3.81\left(\mathrm{q}, J=7.0 \mathrm{~Hz}, 71 \mathrm{H}, \mathrm{OCH}_{2} \mathrm{CH}_{3}\right) ; \delta_{\mathrm{C}}(125.76 \mathrm{MHz}$; $\left.\mathrm{CDCl}_{3} ; \mathrm{TMS}\right)-2.8\left(\mathrm{SiCH}_{3}\right), 18.1\left(\mathrm{OCH}_{2} \mathrm{CH}_{3}\right), 58.9\left(\mathrm{OCH}_{2} \mathrm{CH}_{3}\right) ; \delta_{\mathrm{Si}}$ (99.36 MHz; $\mathrm{CDCl}_{3}$; TMS) -89.04 (Q $\left.{ }^{1}, 8 \mathrm{Si}, \mathrm{SiOSi}(\mathrm{OEt})_{3}\right),-88.95$, $\left(\mathrm{Q}^{1}, 4 \mathrm{Si}, \operatorname{SiOSi}(\mathrm{OEt})_{3}\right),-67.43$ to $-67.45\left(\mathrm{~T}^{3}, 12 \mathrm{Si}, \mathrm{O}_{3} \mathrm{SiMe}\right.$ (overlapping two signals)); HRMS (Electrospray ionization, $2 \mathrm{kV}$ ): calcd for $\mathrm{C}_{84} \mathrm{H}_{216} \mathrm{O}_{60} \mathrm{Si}_{24} \mathrm{Na}^{+}[\mathrm{M}+\mathrm{Na}]^{+}: 2879.8205$; found: 2879.8320 main paragraph text follows directly on here.

\section{Hydrolysis and polycondensation of 12MR-Me-TES}

12MR-Me-TES was dissolved in a mixture of dehydrated ethanol and deuterated ethanol ( $40 \mathrm{vol} \%$ of EtOH- $d_{6}$ ). Then, water and $6 \mathrm{M}$ hydrochloric acid were added to the solution. The molar ratio of 12MR-Me-TES : EtOH + EtOH- $d_{6}: \mathrm{H}_{2} \mathrm{O}: \mathrm{HCl}$ was $1: 96: 36: 0.4$. The mixture was analyzed by NMR spectroscopies after $1 \mathrm{~h}, 3 \mathrm{~h}$, and $6 \mathrm{~h}$ of reaction.

\section{Preparation of 12MR-Me-TES-derived gel}

12MR-Me-TES was dissolved in dehydrated ethanol. Then, water and $6 \mathrm{M}$ hydrochloric acid were added to the solution. The molar ratio of 12MR-Me-TES : EtOH : $\mathrm{H}_{2} \mathrm{O}: \mathrm{HCl}$ was $1: 6006: 360: 0.4$ (EtO : $\mathrm{H}_{2} \mathrm{O}=10$ ), and the concentration of 12MR-Me-TES was $1 \mathrm{wt} \%$. Please note that the molar ratio among those compounds is different from that for the investigation of hydrolysis and polycondensation process of 12MR-Me-TES. After the mixture had been stirred at $1200 \mathrm{rpm}$ at room temperature for $24 \mathrm{~h}$, the solution was cast on a Petri dish. Then, a colorless transparent xerogel was formed by drying at $100{ }^{\circ} \mathrm{C}$ for $10 \mathrm{~min}$ in air. A white powder was obtained by scraping the gel from the Petri dish for analysis (12MR-gel-as). The white powder was heated under an argon atmosphere at $100{ }^{\circ} \mathrm{C}, 200{ }^{\circ} \mathrm{C}$, or $300{ }^{\circ} \mathrm{C}$ for $1 \mathrm{~h}$ (12MR-gelheat100, 12MR-gel-heat200, and 12MR-gel-heat300, respectively) to investigate the possible structural changes of the siloxane network.

\section{Preparation of TEOS-MTES-derived gel}

The mixture of TEOS, MTES, ethanol, water, and $6 \mathrm{M}$ hydrochloric acid was stirred at $1200 \mathrm{rpm}$ at room temperature for $24 \mathrm{~h}$. The molar ratio of TEOS : MTES : $\mathrm{H}_{2} \mathrm{O}: \mathrm{HCl}$ was $1: 1$ : $70: 0.4$. The EtO : $\mathrm{H}_{2} \mathrm{O}$ molar ratio and mass concentration of alkoxides (TEOS + MTES) were the same as those for the aforementioned system of 12MR-Me-TES (EtO : $\mathrm{H}_{2} \mathrm{O}=10$ and $1 \mathrm{wt} \%$, respectively). The hydrolyzed solution was cast on a Petri dish, and a colorless transparent gel was formed by drying at $100{ }^{\circ} \mathrm{C}$ for $10 \mathrm{~min}$ in air. A white powder was obtained by scraping from the Petri dish for analysis (TEOS-MTES-gel). The powder was heated under an argon atmosphere at $100{ }^{\circ} \mathrm{C}$, $200{ }^{\circ} \mathrm{C}$, or $300^{\circ} \mathrm{C}$ for $1 \mathrm{~h}$ (TEOS-MTES-gel-heat100, TEOS-MTESgel-heat200, and TEOS-MTES-gel-heat300, respectively).

\section{Fabrication of membranes from 12MR-Me-TES or mixed TEOS-MTES}

$\alpha$-Alumina particles (a mixture of two types of particles with average diameters of 0.2 and $1.9 \mu \mathrm{m}$ ) were coated onto the outside of porous $\alpha$-alumina tube by using a $\mathrm{SiO}_{2}-\mathrm{ZrO}_{2}$ sol as a binder. To obtain a smooth surface, the tube was calcined in air at $550-600{ }^{\circ} \mathrm{C}$ for $30 \mathrm{~min}$. These procedures were repeated several times to prevent the formation of pinholes in the final membrane. Then, the diluted $\mathrm{SiO}_{2}-\mathrm{ZrO}_{2}$ sol (ca. $\left.0.5 \mathrm{wt} \%\right)$ was coated onto the tube to form an intermediate layer (pore size: 2-3 nm). ${ }^{30}$ After calcination of the tube in air at $550-600{ }^{\circ} \mathrm{C}$ for $30 \mathrm{~min}$, the 12MR-Me-TES-derived layer was fabricated by coating with the hydrolyzed solution of 12MR-Me-TES, which was prepared as the same way as 12MR-gel-as. Finally, the tube was dried and heated at $100{ }^{\circ} \mathrm{C}$ for $1 \mathrm{~h}$ under $\mathrm{N}_{2}$ atmosphere. A TEOS-MTES-derived membrane was fabricated in the same way as the 12MR-Me-TES-derived membrane by using the TEOSMTES sol instead of the 12MR-Me-TES sol. The TEOS-MTES sol was prepared as shown above.

\section{Evaluation of single-gas permeation property}

The experimental apparatus for a single-gas permeation measurement is shown in Fig. $\mathrm{S} 9$ in the ESI $\dagger$ as a schematic. A single gas ( $\mathrm{He}, \mathrm{H}_{2}, \mathrm{CO}_{2}, \mathrm{~N}_{2}, \mathrm{CH}_{4}, \mathrm{CF}_{4}$, or $\mathrm{SF}_{6}$ ) was fed to the outside surface (upstream) of a cylindrical membrane at 200 $\mathrm{kPa}$, and the downside was kept at atmospheric pressure. At first, the values for the single gas permeances were measured at $100{ }^{\circ} \mathrm{C}$, and then the membrane was heat-treated at $200-300{ }^{\circ} \mathrm{C}$ under a $\mathrm{N}_{2}$ atmosphere. After confirming the attainment of a steady state at each temperature by measuring the time course of $\mathrm{N}_{2}$ permeance, the temperature was cooled to $100{ }^{\circ} \mathrm{C}$ and the gas permeance was measured. The permeation rate was 
measured by a bubble film meter. The deviation of the permeation data was less than $5 \%$.

\section{Characterization}

Solution ${ }^{1} \mathrm{H},{ }^{13} \mathrm{C}$, and ${ }^{29} \mathrm{Si}$ NMR spectra were recorded on AVANCE 500 (Bruker) or JNM-ECZ 500 (JEOL) spectrometers with resonance frequencies of $500.13 \mathrm{MHz}, 125.76 \mathrm{MHz}$, and 99.36 MHz, respectively, at room temperature using $5 \mathrm{~mm}$ glass tubes. Tetramethylsilane (TMS) was used as an internal reference at $0 \mathrm{ppm}$. $\mathrm{CDCl}_{3}$ and ethanol- $d_{6}$ were used to obtain lock signals. A small amount of $\mathrm{Cr}(\mathrm{acac})_{3}$ (acac: acetylacetonate) was added as a relaxation agent for ${ }^{29} \mathrm{Si}$ nuclei. ${ }^{13} \mathrm{C}$ NMR spectra were measured with a recycle delay of $2 \mathrm{~s} .{ }^{29} \mathrm{Si}$ NMR spectra were measured with a $45^{\circ}$ pulse and a recycle delay of $10 \mathrm{~s}$. Solid-state ${ }^{29}$ Si MAS NMR spectra were recorded on a JNM-ECX 400 (JEOL) spectrometer with a resonance frequency of $78.7 \mathrm{MHz}$ at room temperature with a $45^{\circ}$ pulse and a recycle delay of $250 \mathrm{~s}$. The recycle delay was set at five times as long as longitudinal relaxation time $\left(T_{1}\right)$ to complete the relaxation of all nuclear spins. The samples were placed in $4 \mathrm{~mm}$ zirconia tubes and spun at $6 \mathrm{kHz}$. The chemical shifts were externally referenced to poly(dimethylsilane) at $-33.8 \mathrm{ppm}$. Solid-state ${ }^{13} \mathrm{C} \mathrm{CP} / \mathrm{MAS}$ NMR spectra were also recorded on a JNM-ECX 400 (JEOL) spectrometer with a resonance frequency of $99.5 \mathrm{MHz}$ at room temperature with a recycle delay of $10 \mathrm{~s}$ and a contact time of 5 ms. The samples were put in $4 \mathrm{~mm}$ silicon nitride tubes and spun at $10 \mathrm{kHz}$. The chemical shifts were externally referenced to the methyl groups of hexamethylbenzene at $17.4 \mathrm{ppm}$. Highresolution electrospray ionization mass (HRMS) analysis was conducted by using an Exactive Plus (Thermo Fisher Scientific) instrument. Low-resolution electrospray ionization mass analysis was conducted by using a JMS-T100 CS AccuTOF (JEOL) instrument. Samples were dissolved in ethanol. Gel permeation chromatography (GPC) was carried out using a LC-9100 with a recycling preparative HPLC system, a refractive index (RI) detector (Japan Analytical Industry Co., Ltd.) and two types of crosslinked polystyrene packed columns (JAIGEL-1H and JAIGEL-2H; exclusion limits of 1000 and 2000, respectively, and theoretical plate of 13000 ). Chloroform was used as an eluent with a flow rate of $3.5 \mathrm{~mL} \mathrm{~min}^{-1}$. FT-IR spectra were recorded on a FT/IR-6100 (JASCO) spectrometer at ambient temperature. The FT-IR spectra were measured using $\mathrm{KBr}$ disk technique under vacuum conditions. Powder XRD patterns were recorded on a RINT-Ultima III (RIGAKU) diffractometer with $\mathrm{Cu} \mathrm{K} \alpha$ radiation at $40 \mathrm{kV}$ and $40 \mathrm{~mA}$.

\section{Conflicts of interest}

There are no conflicts to declare.

\section{Acknowledgements}

The authors greatly appreciate Dr T. Shibue and Mr N. Sugimura (Materials Characterization Central Lab., Waseda University) for solid state NMR and HRMS measurements, respectively. The authors also thank $\mathrm{Mr}$ S. Saito (Waseda
University) for his help on separation by GPC and $\mathrm{Mr}$ E. Yamamoto, Mr S. Mori, and Ms. S. Uchida (Waseda University) for their help in the preparation of the TEOS-MTES sol. M. Y. is thankful to the JX-Waseda Research Fund for Young Researchers and Japan Chemical Industry Association for a fellowship (Human Resources fostering Program in Chemistry). This work was supported in part by JSPS KAKENHI (Grantin-Aid for Scientific Research(B), No. 15H03879).

\section{Notes and references}

1 M. E. Davis, Nature, 2002, 417, 813-821.

2 T. Tsuru, J. Sol-Gel Sci. Technol., 2008, 46, 349-361.

3 C. Sanchez, G. J. d. A. A. Soler-Illia, F. Ribot, T. Lalot, C. R. Mayer and V. Cabuil, Chem. Mater., 2001, 13, 30613083.

4 A. Shimojima and K. Kuroda, Chem. Rec., 2006, 6, 53-63.

5 K. Kuroda, A. Shimojima, K. Kawahara, R. Wakabayashi, Y. Tamura, Y. Asakura and M. Kitahara, Chem. Mater., 2014, 26, 211-220.

6 J. S. Ritch and T. Chivers, Angew. Chem., Int. Ed., 2007, 46, 4610-4613.

7 A. Decken, F. A. LeBlanc, J. Passmore and X. Wang, Eur. J. Inorg. Chem., 2006, 4033-4036.

8 A. Decken, J. Passmore and X. Wang, Angew. Chem., Int. Ed., 2006, 45, 2773-2777.

9 T. S. Cameron, A. Decken, I. Krossing, J. Passmore, J. M. Rautiainen, X. Wang and X. Zeng, Inorg. Chem., 2013, 52, 3113-3126.

10 M. Borsari, G. Gavioli, C. Zucchi, G. Pályi, R. Psaro, R. Ugo, O. I. Shchegolikhina and A. A. Zhdanov, Inorg. Chim. Acta, 1997, 258, 139-144.

11 Y. A. Molodtsova, Y. A. Pozdnyakova, I. V. Blagodatskikh, A. S. Peregudov and O. I. Shchegolikhina, Russ. Chem. Bull., 2003, 52, 2722-2731.

12 S. D. Korkin, M. I. Buzin, E. V. Matukhina, L. N. Zherlitsyna, N. Auner and O. I. Shchegolikhina, J. Organomet. Chem., 2003, 686, 313-320.

13 O. I. Shchegolikhina, E. V. Matukhina, A. A. Anisimov, Y. A. Molodtsova, M. I. Buzin, K. A. Lyssenko and A. M. Muzafarov, Macroheterocycles, 2016, 9, 11-16.

14 J. Han and S. Zheng, Macromolecules, 2008, 41, 4561-4564. 15 Y. Yi, N. Liu, L. Li and S. Zheng, RSC Adv., 2016, 6, 8780287807.

16 Y. Sugahara, S. Okada, S. Sato, K. Kuroda and C. Kato, J. NonCryst. Solids, 1994, 167, 21-28.

17 R. J. Hook, J. Non-Cryst. Solids, 1996, 195, 1-15.

18 D. A. Loy, B. M. Baugher, C. R. Baugher, D. A. Schneider and K. Rahimian, Chem. Mater., 2000, 12, 3624-3632.

19 Y. A. Pozdniakova, K. A. Lyssenko, A. A. Korlyukov, I. V. Blagodatskikh, N. Auner, D. Katsoulis and O. I. Shchegolikhina, Eur. J. Inorg. Chem., 2004, 1253-1261.

20 V. Pashchenko, B. Brendel, B. Wolf, M. Lang, K. Lyssenko, O. Shchegolikhina, Y. Molodtsova, L. Zherlitsyna, N. Auner, F. Schütz, M. Kollar, P. Kopietz and N. Harrison, Eur. J. Inorg. Chem., 2005, 4617-4625. 
21 L. Zherlitsyna, N. Auner, M. Bolte, Y. Pozdniakova, O. Shchegolikhina, K. Lyssenko, V. Pashchenko, B. Wolf, M. Lang, F. Schütz, M. Kollar, F. Sauli and P. Kopietz, Eur. J. Inorg. Chem., 2007, 4827-4838.

22 I. V. Blagodatskikh, Y. A. Molodtsova, Y. A. Pozdnyakova, O. I. Shchegolikhina and A. R. Khokhlov, Colloid J., 2008, 70, 407-415.

23 A. N. Bilyachenko, A. N. Kulakova, M. M. Levitsky, A. A. Petrov, A. A. Korlyukov, L. S. Shul'pina, V. N. Khrustalev, P. V. Dorovatovskii, A. V. Vologzhanina, U. S. Tsareva, I. E. Golub, E. S. Gulyaeva, E. S. Shubina and G. B. Shul'pin, Inorg. Chem., 2017, 56, 4093-4103.

24 J. C. Pouxviel, J. P. Boilot, J. C. Beloeil and J. Y. Lallemand, J. Non-Cryst. Solids, 1987, 89, 345-360.
25 R. J. R. Uhlhorn and A. J. Burggraaf, in Inorganic Membranes Synthesis, Characteristics and Applications, Springer, Netherlands, Dordrecht, 1991, pp. 155-176.

26 J. Wang, M. Kanezashi, T. Yoshioka and T. Tsuru, J. Membr. Sci., 2012, 415-416, 810-815.

27 W. Puthai, M. Kanezashi, H. Nagasawa and T. Tsuru, Sep. Purif. Technol., 2016, 168, 238-247.

28 W. Puthai, M. Kanezashi, H. Nagasawa and T. Tsuru, J. Membr. Sci., 2017, 524, 700-711.

29 Y. A. Molodtsova, K. A. Lyssenko, I. V. Blagodatskikh, E. V. Matukhina, A. S. Peregudov, M. I. Buzin, V. G. Vasil'ev, D. E. Katsoulis and O. I. Shchegolikhina, J. Organomet. Chem., 2008, 693, 1797-1807.

30 M. Kanezashi, S. Miyauchi, H. Nagasawa, T. Yoshioka and T. Tsuru, J. Membr. Sci., 2014, 466, 246-252. 